\title{
Industry 4.0 and Preparedness of the Workforce: A Bibliometric Analysis
}

DOI 10.18267/pr.2021.krn.4816.12

\author{
Eva Křenková 1 - Květa Olšanová ${ }^{2}$ \\ ORCID iD: 0000-0003-3820-7608 ${ }^{1}, 0000-0002-0010-1480^{2}$ \\ eva.krenkova@vse.cz, kveta.olsanova@vse.cz \\ 1, 2 Prague University of Economics and Business, Faculty of International Relations, \\ Department of International Business \\ Prague, Czech Republic
}

\begin{abstract}
The discussion related to the implementation of Industry 4.0 elements has brought researchers' attention to the changes of requirements on the workforce. The current research focuses on identifying the core competencies related to Industry 4.0 and strategies towards their development. The purpose of this article is to observe the topic of competencies, skills, and education amongst the research articles related to Industry 4.0, including its development over the last ten years, identify the current trends in the literature, and make suggestions for future research. Bibliometric analysis was conducted to conclude that research focus related to the workforce adaptation in terms of their skills, competencies, and the requirements from formal education associated with Industry 4.0 needs are not amongst the most discussed related to Industry 4.0 .
\end{abstract}

Keywords: industry 4.0, digitalization, workforce, competencies, skills, education

JEL Classification codes: H52; M10; O33; I20

\section{INTRODUCTION}

One of the recent questions asked is whether the industry sectors can successfully operate in the digital environment and face future challenges. The World Economic Forum, WEF (2020) predicts that by 2025 , humans' work and machines measured in time units will be equal. Tasks to be taken over by the robots are most commonly described as routine repetitive prone to error tasks (Deloitte, 2019), which result in handling over more complex tasks and problemsolving to the employees. Although the implementation of digital technologies eases work on all managerial levels, at the same time, it causes many new organizational challenges. Schneider (2018) concluded conformity in the practitioners' and academics' perspective on the most critical managerial challenges related to digital transformation. This being namely the openness to change, impact on working life, establishing a culture of experimentation, qualified employees, and building of digital capabilities. Companies' management needs to adopt decisions in strategy, planning and implementation, cooperations and network development, business models, challenge the changing environment and leadership questions, and last but not least, search for employees with the necessary hard and soft skills and competencies and manage human resources in general.

This article aims to present a comprehensive evaluation of the literature related to the requirements of the workforce's skills and competencies in the technologically evolving environment framed by Industry 4.0. Moreover, the emphasis is put on the education system and how it reflects the technological changes. The article is structured as follows. Firstly the main terms such as Industry 4.0, skills, and competencies are defined. The research questions 
are derived from the literature review and addressed by using bibliometric analysis. Finally, the conclusion with recommendations for future research is suggested, followed by research limitations.

\section{LITERATURE REVIEW}

The term "Fourth Industrial Revolution" (4IR) has become commonly used in 2016. The digital transformation has been discussed already before when Klaus Schwab has published his eponymous book (Philbeck \& Davis, 2018) as a broad term to frame and analyze the impact of emerging technologies on society in the 21st century, while Industry 4.0 refers to" recent technological advances where the internet and supporting technologies (e.g., embedded systems) serve as a backbone to integrate physical objects, human actors, intelligent machines, production lines, and processes across organizational boundaries to form a new kind of intelligent, networked and agile value chain" (Schumacher et al., 2016, p. 162).

The implementation of Industry 4.0 concepts results in what Dombrowski and Wangner (2014) describe as job profile shift from specific work tasks and execution of manufacturing to interdisciplinary cooperation and "process-oriented tasks with frequently changing content and the necessary change of the competencies from specific technical capabilities, clear thinking in single processes and accurate execution of the centrally planned work tasks to complexity, abstraction, and problem-solving abilities, thinking in overlapping processes and selforganization (Dombrowski \& Wangner, 2014, p. 102).

Skills are defined in the European Qualification Framework, EQF, as "the ability to apply knowledge and use know-how to complete tasks and solve problems." In the context of the $E Q F$, skills are described as cognitive or practical (EQF, 2017). Based on WEF future job survey (WEF, 2020), the current top ten skills are analytical thinking and innovation; active learning and learning strategies; complex problem-solving, critical thinking and analysis; creativity, originality, and initiative; leadership and social influence; technology use, monitoring, and control; technology design and programming; resilience, stress tolerance, and flexibility; reasoning, problem-solving and ideation.

Competencies are observed and evaluated in practical learning when identifying and solving a problem (Abele et al., 2017). Kinkel et al. (2017, p. 324) define competence as "the individual dispositional ability and readiness to act successfully and self-organized when facing novel, unstructured or complex situations or tasks and the ability to develop solutions for future cases". In the EQF, the competence is defined as "proven ability to use knowledge, skills and personal, social and methodological abilities, in work or study situations and professional and personal development" (EQF, 2017, Annex 1).

Skills and competencies are developed through education, training, and experience (Skinner et al., 2004). Although the WEF (2020) states that the skills gap remains to be high, there has been a significant shift in the education system in the developed countries towards the readiness for changes related to Industry 4.0 by bringing students and their needs to the center of education as opposed to the earlier teacher-centered focus, this being in many countries overcome (Miranda et al., 2019).

The changes related to Industry 4.0 are reflected in new study programs, new technologies being employed in education and training, and the quality of study programs and professional practice. The study programs in data science and analytics are emerging. Chen et al. (2012) stress that these study programs should be interdisciplinary, including analytical and IT skills, domain knowledge (e.g., business), and communication skills development. Analytical skills development should also be enhanced in existing programs, e.g., supply chain management, 
where the analytical skills are taught together with the domain knowledge (Waller \& Fawcett, 2013).

The use of technologies can support education and training. Technologies have been widely installed and used to share data amongst teachers and students (Bond et al., 2018). New learning methods based on technologies are being incorporated, and innovative facilities and labs are being created (Miranda et al., 2019, Mian et al., 2020, Ramirez-Mendoza et al., 2018). Researchers supporting the wide use of the virtual reality technology argue with improved outcomes of students (Merchant et al., 2013), working in the flow state of mind (Hwang, 2012), cost efficiency, and real environment situations training with possible adjustments to different environments or adaptations (Kaasinen et al., 2020). Learning factories can exist in the form of physical factories, digital factories focusing on planning or simulations, and hybrid factories. Competencies to be developed are mainly related to future problems solving ( Abele et al., 2017; Kaasinen et al., 2020). There is potential for developing virtual training skills; the question remains, how best should the virtual training be targeted? It seems to be a complementary method to other teaching methods. Merchant et al. (2013) support the use of technology in education, still question whether the collaborative skills can be developed because "students performance is enhanced when they conduct the game play individually than in a group "(Merchant et al., 2013, p. 29).

The quality of education is another factor that should not be overlooked. On the one hand, talented young school children need to be supported to become experts in their fields (Subortnik, 2011); on the other hand, attitude towards learning needs to be developed into lifelong learning. The literature suggests that the belief that technology in education can help build attitudes towards learning and ease the lifelong learning process inevitable in a fastchanging environment (Bond et al., 2018; Ciolacu et al., 2018). Concerning the qualitative aspects of education, creativity should not be limited by the teacher's personality restricting students' thoughts and expressions. The respect for seniority is still incorporated in some cultures (Buasuwan, 2018) but can be the case in individual cases elsewhere. High emphasis should also be put on cooperation and interdisciplinary project solving (Ramirez-Mendoza et al., 2018). Dash et al. (2019) highlight the importance of combining theoretical knowledge and practical experience. Nga \& Shamuganathan (2010) support incorporating sustainability and social responsibility principles into higher education programs.

\section{Industry 4.0 related competencies}

The research of Hecklau et al. (2016) has gained attention by scholars (Quatrociocchi et al., 2018; Simic \& Nedelko, 2019) by aggregating the competencies related to Industry 4.0 into four segments, namely social, personal, methodological, and technical. These were updated one year later as (i) social competencies including communication and cooperation skills and leadership competence; (ii) methodological competencies that encompass analytical competence, complex problem solving, and decision making; (iii) personal competencies including creativity, willingness to learn, flexibility and adaptability; and (iv) domain competencies with digital networks, digital security, process understanding, coding, and interdisciplinary competence. The authors conclude that the higher the technology integration, the more emphasis is placed on analytical competence (Hecklau et al., 2017).

Müller et al. (2018) suggest searching for drivers of the implementation of Industry 4.0 by working with the classification of adequate personal, social/interpersonal, action-related, and domain-related competencies.

Miranda et al. (2019) suggest the need to develop five predefined core competencies, namely, critical thinking, creativity and innovation, cooperation, collaboration, and communication. Critical thinking development leads to developed analytical skills; creativity and innovation being fundamental to develop new ideas; cooperation in practical exercise leads to independent work, responsibility, communication, and collaboration. The view of open 
innovation laboratories presented by Miranda et al. (2019) is following the vision of Cioalacu et al. (2018), who promote engineering skills and competencies such as innovation, complex problem solving, knowing in action, modular quality control, artificial intelligence methods, and rapid prototyping, and leadership competencies such as creativity, people management, critical thinking, reflection in action, association and negotiation, and AI-based decision.

Kazancoglu and Ozkan-Ozen (2018) suggested new criteria for personnel selection environments according to the changes in job profiles due to Industry 4.0 from an operations management perspective. They have used 11 criteria based on the frequency used in the literature (Dombrowski \& Wagner, 2014; Lorenz et al., 2015) and sorted the importance levels of selected criteria as follows (in descending order), concluding that for Industry 4.0, the teamwork and organizational understanding are priorities:

- the ability to deal with complexity and problem solving;

- $\quad$ thinking in the overlapping process;

- flexibility to adapt to new roles and work environments;

- continual interdisciplinary learning and cooperation;

- organizational and processual understanding;

- trust in new technologies;

- the ability of fault and error recovery;

- combining know-how related to a specific job or process;

- $\quad$ ability to interact with modern interfaces;

- awareness of IT security and data protection;

- $\quad$ knowledge on IT and production technologies.

There are several articles in which the core competencies and skills were identified in a systematic literature review (Hecklau et al., 2017; Hernandez-de-Menendez et al., 2020).

To the authors' best knowledge, no research was done to explore the importance of Industry 4.0 related education, skills, and competencies. Therefore, based on the indications from the literature review, the following research questions are suggested to fulfill the article objectives:

RQ1: What are the most researched topics related to Industry 4.0, and what is the position of formal education and skills \& competencies associated with articles dedicated to Industry 4.0 ?

RQ2: To what extent has the approach towards the academic research of education and skills \& competencies related to Industry 4.0 developed over the last ten years?

RQ3: What are the requirements for formal education and skills \& competencies related to Industry 4.0 most frequently discussed in the literature associated with Industry 4.0?

\section{METHODOLOGY}

The methodology used in the current research is bibliometric analysis. Bibliometric studies are useful when there is a need to collect evidence from previously published research articles. The high number of articles published worldwide makes it impossible for researchers to remain current with global science (Aria \& Cuccurullo, 2017). This approach makes it possible to map the continually changing science. The analysis was conducted in $\mathrm{R}$ software using a bibliometric package for comprehensive science mapping analysis after downloading the records into the BibTeX format.

To answer RQ1, the data were retrieved from the database Scopus and Web of Science (WoS) in January 2021. The search for the set phrase "industry 4.0" was conducted. The two databases were used to learn about the potential difference amongst the sources included in a different database. The search included the titles, keywords, and abstracts. 
To answer RQ2 and RQ3, the query string was extended to capture Industry 4.0 phenomenon in a more extended period. The most relevant out of the top 20 keywords derived from research articles related to Industry 4.0 were used to substitute the term Industry 4.0. Words with a general meaning, such as manufacturing or sustainability, were excluded to prevent a large dataset that might result in much noise (Chen et al., 2021). From 9301 articles, only sources from social science and engineering were selected through the WoS categories. Visualization of results was done in $\mathrm{R}$.

\section{RESULTS AND DISCUSSION}

To answer the RQ1: "What are the most researched topics related to Industry 4.0, and what is the position of formal education and skills \& competencies associated with articles dedicated to Industry 4.0?" a search revealed 4673 records from WoS and 4417 from Scopus, all containing the phrase "Industry 4.0" in the title, keywords, or abstract.

The cluster analysis revealed the areas of research focus (Figure 1). The identified clusters in WoS are industry and smart production, manufacturing and big data, machine learning, artificial intelligence and IoT, internet of things and blockchain, optimization, and additive manufacturing. Similar results were derived from Scopus. Since there were no outcomes related to the workforce, capabilities, skills, or education found among the clusters, it can be concluded that the educational topics seemed to have less attention among the currently published Industry 4.0 articles.

Fig. 1 Clusters in Industry 4.0 search

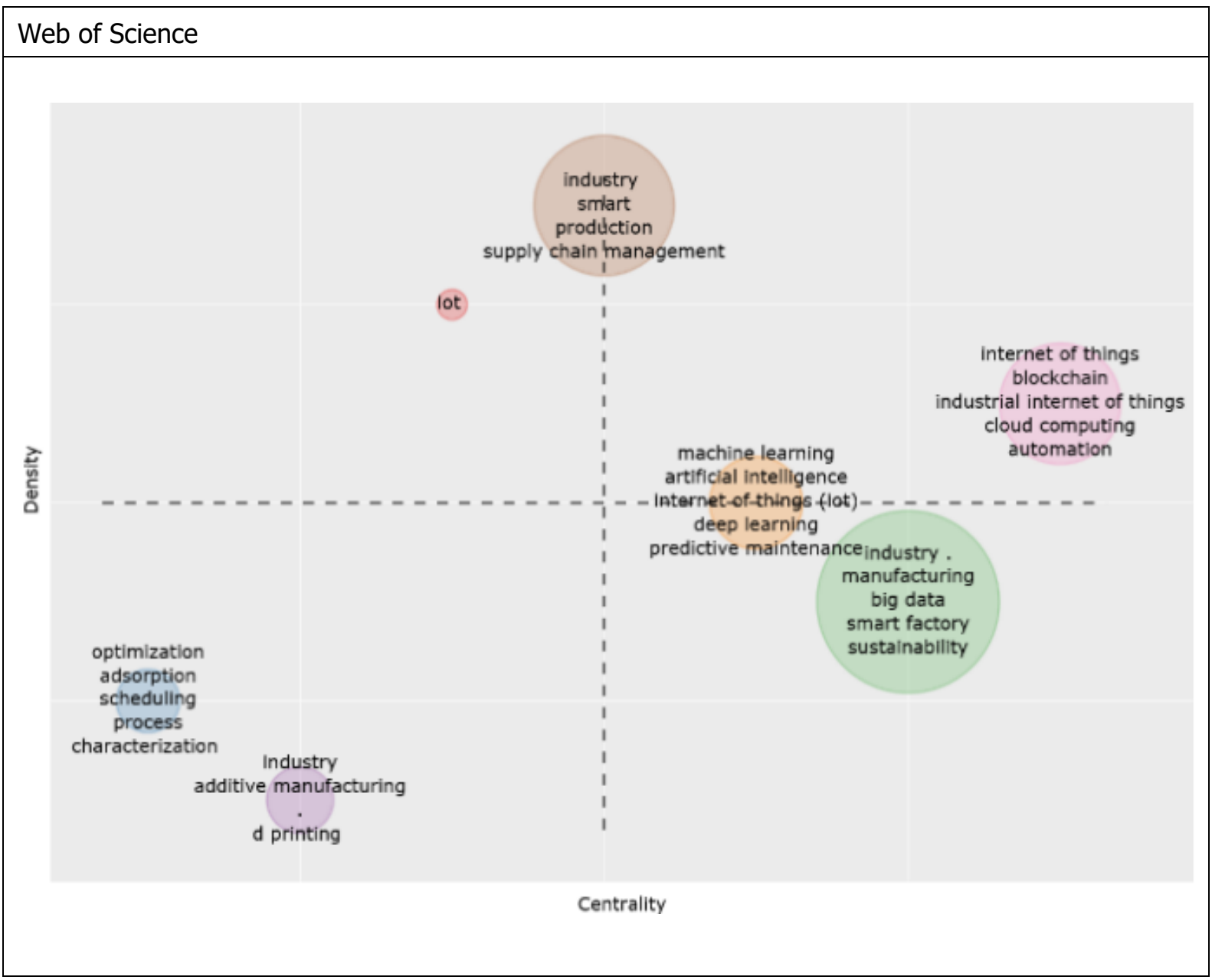




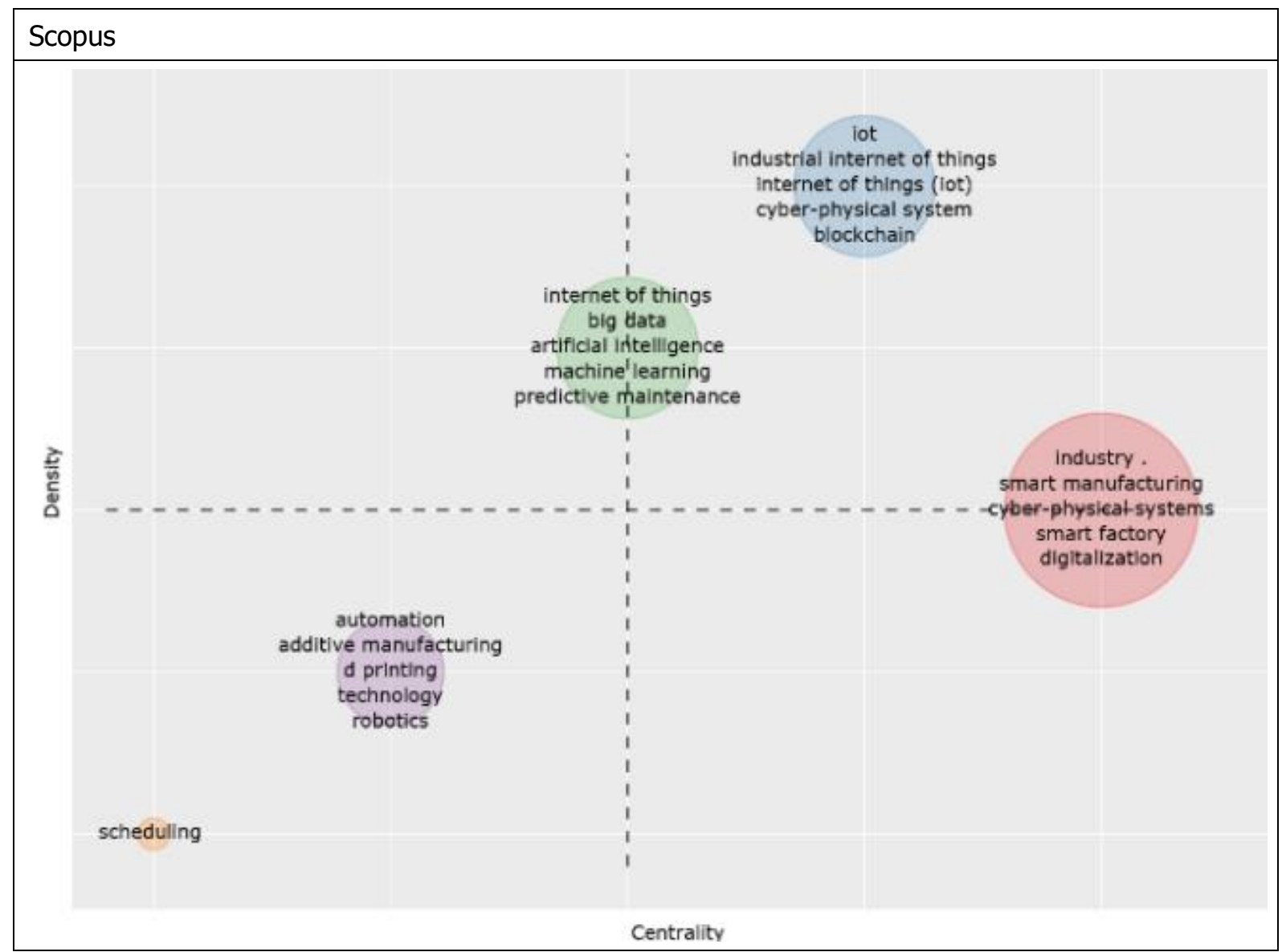

Source: authors based on data from WoS and Scopus

The co-occurrence analysis of articles' keywords retrieved from WoS and Scopus (Figure 2) was done to confirm the above, showing that any words related to the RQ1 are not among those most frequently co-occurring with Industry 4.0 (Figure 2). The top 20 keywords are listed in Table 1.

Tab. 1 Top 20 most frequently co-occuring articles' keywords related to Industry 4.0

\begin{tabular}{|l|l|l|l|l|l|}
\hline Industry 4.0 & 1196 & Digitalization & 89 & Optimization & 58 \\
\hline $\begin{array}{l}\text { Internet of things, } \\
\text { IoT }\end{array}$ & 267 & Smart manufacturing & 88 & Cloud computing & 57 \\
\hline Manufacturing & 127 & Machine learning & 80 & $\begin{array}{l}\text { Industrial Internet of } \\
\text { things }\end{array}$ & 56 \\
\hline Big data & 103 & Innovation & 78 & Artificial intelligence & 54 \\
\hline Sustainability & 95 & Industry & 76 & Simulation & 54 \\
\hline Smart factory & 93 & Blockchain & 62 & Technology & 52 \\
\hline $\begin{array}{l}\text { Cyber-physical } \\
\text { systems }\end{array}$ & 92 & Digital twin & 60 & & \\
\hline
\end{tabular}

Source: authors based on data from WoS 
Fig. 2 Co-occurrence of Industry 4.0 and articles' keywords in WoS 2010

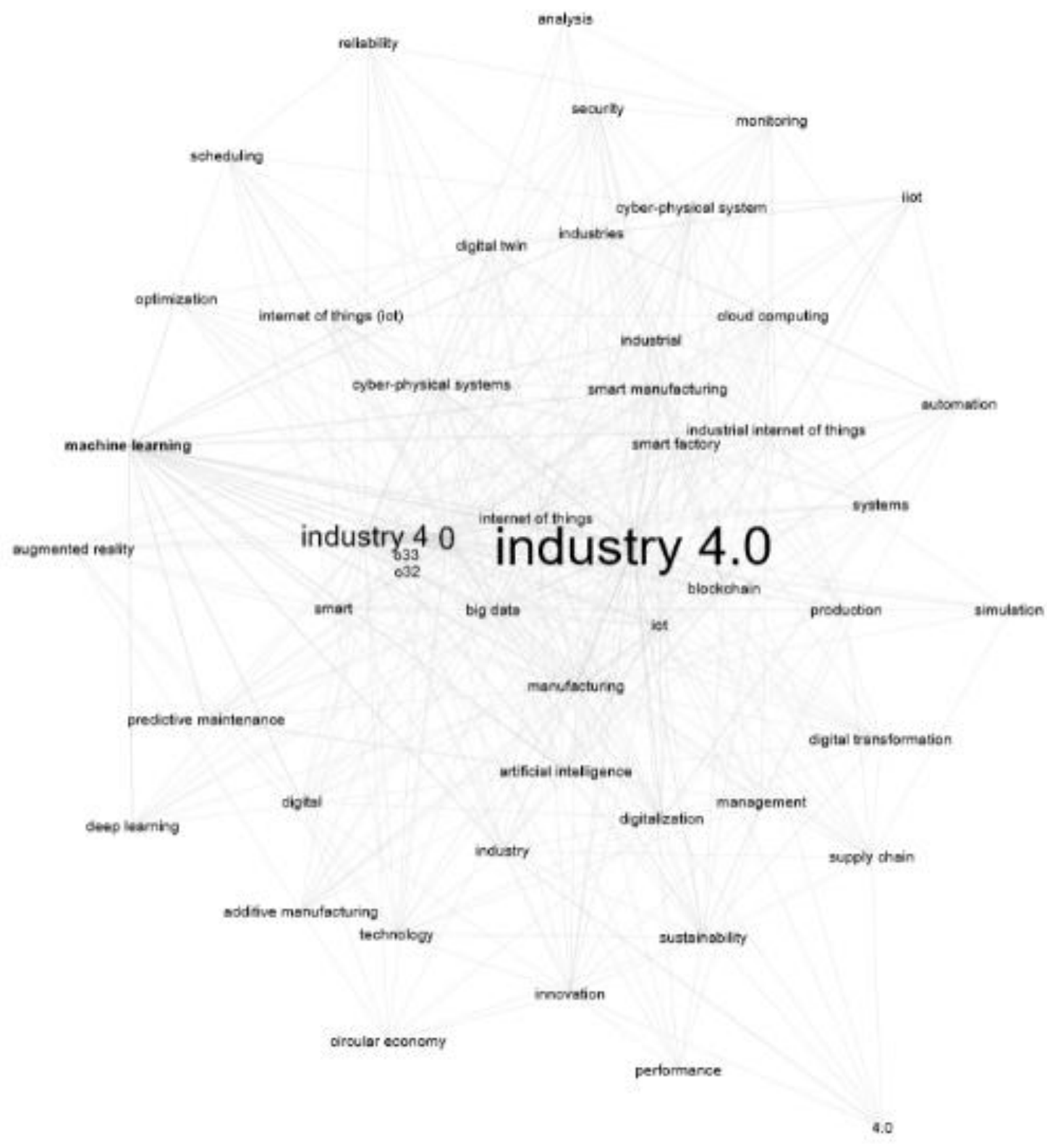

Source: Authors based on data from WoS and Scopus

Following RQ2: "To what extent has the approach towards the academic research of education and skills \& competencies related to Industry 4.0 developed over the last ten years?"; most frequent articles' keywords from the WoS dataset (Table 1) were used to form the following query string applied with limitation to years 2010 - 2021: ("industry 4.0" OR "internet of things" OR "big data" OR "smart factory" OR "cyber-physical systems" OR "digitalization" OR "smart manufacturing" OR "machine learning" OR "innovation" OR "blockchain" OR "cloud computing" OR "artificial intelligence" OR "simulation") AND (education) AND ("skills" OR "capability" OR "capabilities" OR "competency" OR "competencies" OR "competence" OR "competences").

The search resulted in retrieving 4164 records from WoS. As visualized in Figure 3, the topic has gained growing attention over the last few years. The number of published articles closely 
related to Industry 4.0 and education, skills \& capabilities was growing from 2015 to the peak in 2020, with 393 articles published and quoted in WoS in 2015, 385 in 2016, 533 in 2017, 582 in 2018, 753 in 2019, and 868 in 2020. Therefore, the topic is within the Industry 4.0 articles relatively new, and the growing number of articles over the past few years indicates increasing interest. The roots of the trend are in Europe and North American countries, with the worldwide spread that was in its early years encouraged by the collaboration of the firstmentioned and Chinese authors. In 2020, there were already authors in all the continents who published related articles.

\section{Fig. 3 Country collaboration map}

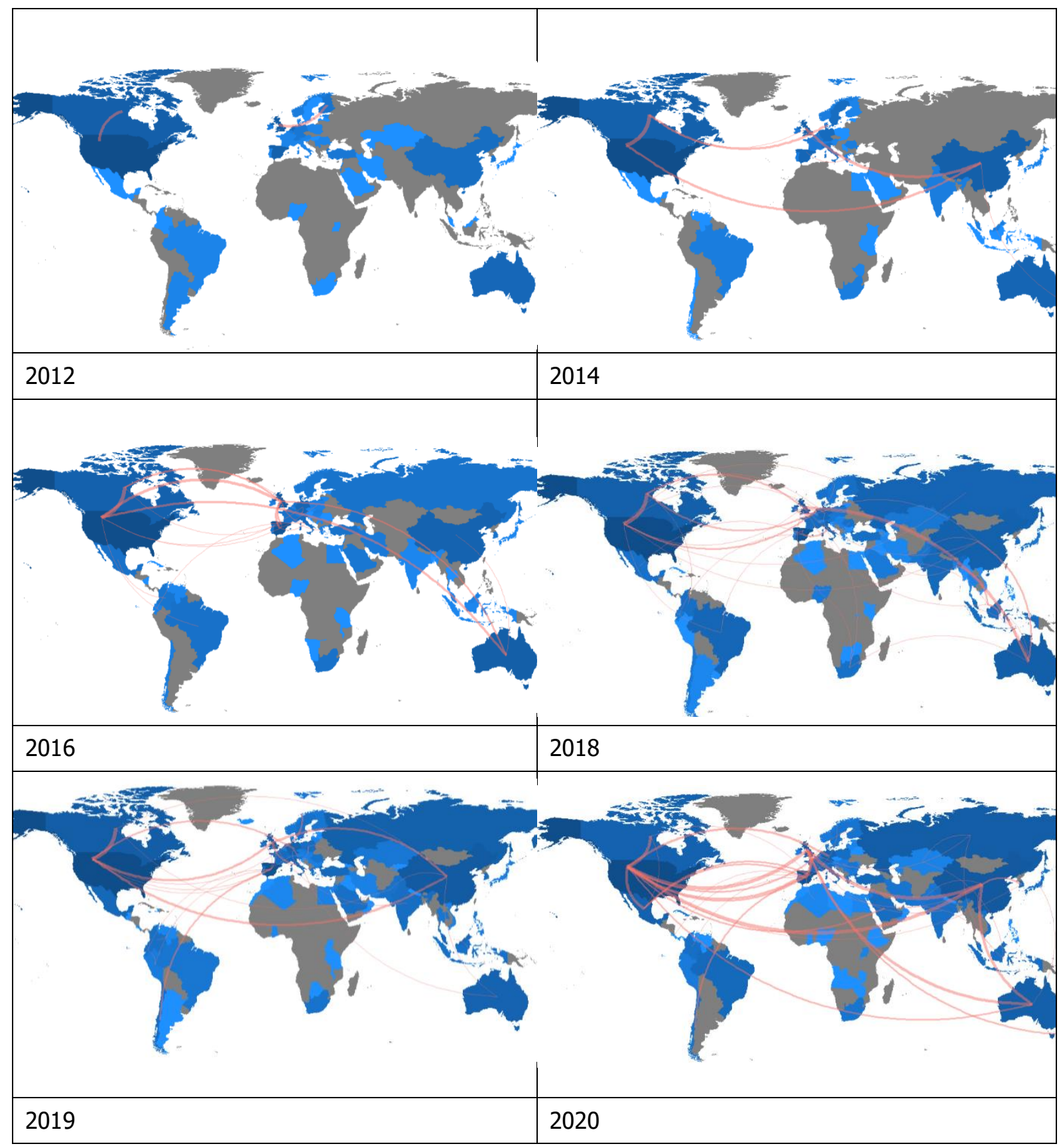

Source: Authors based on data from WoS

Further analysis of the data retrieved from WoS addresses the RQ3 - "What are the requirements for formal education and skills \& competencies related to Industry 4.0 most 
frequently discussed in the literature associated with Industry 4.0?" At this stage, the analysis would present the citation analysis, subsequently being followed by the occurrence of articles' keywords (Table 2).

Tab. 2 The most cited articles published in the period related to education OR workforce readiness $(2010-2021)$

\begin{tabular}{|l|l|l|}
\hline Rank & Document & Citations \\
\hline 1 & $\begin{array}{l}\text { MATPOWER: Steady-State Operations, Planning, and Analysis Tools for } \\
\text { Power Systems Research and Education (Zimmerman et al., 2011) }\end{array}$ & 2774 \\
\hline 2 & $\begin{array}{l}\text { Business Intelligence and Analytics: From Big Data to Big Impact (Chen et } \\
\text { al., 2012) }\end{array}$ & 1764 \\
\hline 3 & $\begin{array}{l}\text { Data Science, Predictive Analytics, and Big Data: A Revolution That Will } \\
\text { Transform Supply Chain Design and Management (Waller \& Fawcett, 2013) }\end{array}$ & 453 \\
\hline 4 & Do Institutions Matter for Regional Development? (Rodríguez-Pose, 2013) & 401 \\
\hline 5 & $\begin{array}{l}\text { Effectiveness of virtual reality-based instruction on students' learning } \\
\text { outcomes in K-12 and higher education: A meta-analysis (Merchant et al., } \\
\text { 2014) }\end{array}$ & 387 \\
\hline 6 & $\begin{array}{l}\text { Rethinking Giftedness and Gifted Education: A Proposed Direction Forward } \\
\text { Based on Psychological Science (Subotnik et al., 2011) }\end{array}$ & 304 \\
\hline 7 & $\begin{array}{l}\text { Open Innovation: Past Research, Current Debates, and Future Directions } \\
\text { (Lichtenthaler, 2011) }\end{array}$ & 291 \\
\hline 8 & $\begin{array}{l}\text { The Influence of Personality Traits and Demographic Factors on Social } \\
\text { Entrepreneurship Start-Up Intentions (Nga \& Shamuganathan, 2010) }\end{array}$ & 210 \\
\hline 9 & $\begin{array}{l}\text { Game-based learning and 21st-century skills: A review of recent research } \\
\text { (Qian \& Clarc, 2016) }\end{array}$ & 184 \\
\hline 10 & $\begin{array}{l}\text { An online game approach for improving students' learning performance } \\
\text { in web-based problem-solving activities (Hwang et al., 2012) }\end{array}$ & 140 \\
\hline
\end{tabular}

Source: authors based on data from WoS

The citation analysis and the analysis of articles' keywords uncovered some major research topics related to Industry 4.0 with the focus on education and skills \& competencies. The analysis confirmed that the emphasis is put on innovation, higher education, and educational innovation (Figure 4). Education is suggested as one of the institutions contributing to innovations (new technologies, products, and processes). It also determines the absorption of innovations generated elsewhere (Rodríguez-Pose, 2013). Innovative education can support readiness to adopt new technologies and decrease the risk of a lack of qualified employees. The growing number of articles published concerning education (Figure 4) reflects this field's growing emphasis. The need to adapt the education and training programs to the changing conditions and requirements is present in most cited articles (Chen et al., 2012; Waller \& Fawcett, 2013). Within innovative study programs, the emphasis is suggested on analytical skills development. 
Fig. 4 Most relevant articles' keywords
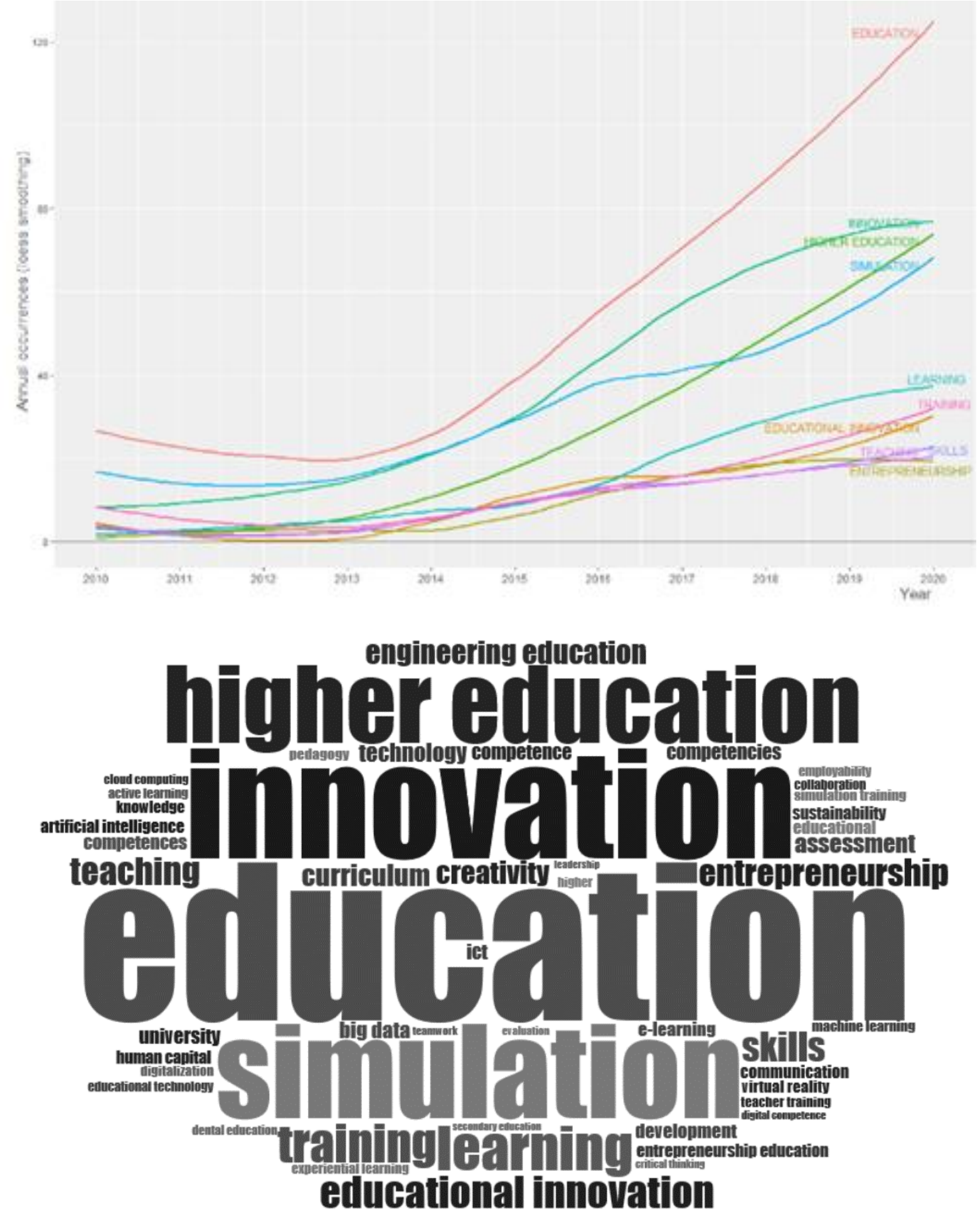

Source: Authors based on data from WoS

In the keywords co-occurrence analysis, teacher's training is also cited with the direct link to digital competence, ICT (information and communication technology), higher education in general, and innovation. This finding is supported by the research of Waller and Fawcett (2013), who conclude with the statement that the focus on analytical skills connected with the domain knowledge is expected not only from the graduates but also from academics. Skilled and motivated educators are important for developing the competencies that will be needed 
to manage work in the future (Miranda et al., 2020). Competence in the present study appears with creativity, communication, collaboration, data science, digitalization, and digital technology.

Technologies can support active learning. Amongst the used tools, most commonly cited is simulation that is co-occurring with training, virtual reality, engineering, and medical education. Working with more sophisticated technologies will pose new pressure and requirements on employees (Rauch, 2020). Even if employees have a positive attitude towards training in new technologies, there must be an evident and apparent use of the gained skills (Kaasinen et al., 2020). Professional training can also be enhanced using technologies such as simulations or virtual reality. These should be used the way to be adjusted to the individual needs and environments. In recent research, the pressure on developing the ability to learn and accelerate learning has been expressed (Rauch, 2020).

Essential skills and competencies related to Industry 4.0 have been defined. The top ten skills listed by WEF (2020) support the necessity to develop an attitude towards lifelong learning. Future study programs should initiate the attitude towards learning. With the right programs in place, the education system can partly take over the companies' burden in training, retraining, re-skilling, and life learning, supporting further cooperation between the business and education, and research sectors.

\section{CONCLUSION}

The current study suggests that the term Industry 4.0 is in the research articles linked to manufacturing, smart factories, supply chain management, technologies such as IoT, Big Data, digital technologies, artificial intelligence, blockchain, and cloud computing. The frequency of the articles exploring the education, skills \& competencies related to Industry 4.0 is lower, and none of the education-related keywords was found amongst the vital topic associated with Industry 4.0. Still, the number of published articles in this field has been growing over the last few years and encompasses all continents. A growing research interest related to education is emphasizing higher education and innovation. Study programs need to proceed with the evolution and be adjusted to comply with society's future needs. Increased emphasis is in the research articles on analytical skills that support fast decision-making when massive data are available. Big data analytics should not be overestimated as domain knowledge is equally essential (Waller \& Fawcett, 2013) and should go hand in hand with analytical skills.

To conclude, there is a space for further research related firstly to systematic literature review of the context of understanding the readiness of the education system to the changes faced by Industry 4.0, followed by case studies of the countries with the best fit of the education system and industry need, further explored by empirical research of the match between industry expectations and system readiness.

When evaluating the research results of the present article, the study limitations need to be considered. One of them is the methodology itself in terms of the inability to assess the search context. The search based on keywords can also produce articles that include the keywords in their title, keywords or abstracts, but are of a different focus (Saha et al., 2019). The selection of databases can also impact the research results. 


\section{REFERENCES}

Abele, E., Chryssolouris, G., Sihn, W., Metternich, J., ElMaraghy, H., Seliger, G., Sivard, G., ElMaraghy, W., Hummel, V., Tisch, M., \& Seifermann, S. (2017). Learning factories for future oriented research and education in manufacturing. CIRP annals-Manufacturing Technology, 66(2), 803-826. https://doi.org/10.1016/j.cirp.2017.05.005

Aria, M. \& Cuccurullo, C. (2017) Bibliometrix: An R-tool for comprehensive science mapping analysis. Journal of Informetrics, 11, 959-975. https://doi.org/10.1016/j.joi.2017.08.007

Bond, M., Marín, V.I., Dolch, C., Bedenlier, S., \& Zawacki-Richter, O. (2018). Digital transformation in German higher education: student and teacher perceptions and usage of digital media. In Int J Educ Technol High Educ 15, 48. https://doi.org/10.1186/s41239-0180130-1

Buasuwan, P. (2018) Rethinking Thai higher education for Thailand 4.0. Asian Education and Development Studies. 7(2), 157-173. https://doi.org/0.1108/AEDS-07-2017-0072

Chen, H., Chiang, R.H.L, \& Storey, V.C. (2012) Business Intelligence and Analytics: From Big Data to Big Impact. MIS Quarterly. 36(4), 1165-1188. https://doi.org/10.2307/41703503.

Chen, X., Zou, D., Xie, H., \& Wang, F.L. (2021) Past, present, and future of smart learning: a topic-based bibliometric analysis. International Journal of Educational Technology in Higher Education. 18(2). https://doi.org/10.1186/s41239-020-00239-6

Ciolacu, M., Tehrani, A.F., Binder, L., \& Svasta, P.M. (2018) Education 4.0-artificial intelligence assisted higher education: Early recognition system with machine learning to support students' success. In 2018 IEEE 24th International Symposium for Design and Technology in Electronic Packaging(SIITME), pp. 23-30.

Dash, D., Farooq, R., Panda, J.S., \& Sandhyavani, K.V. (2019) Internet of Things (IoT): The New Paradigm of HRM and Skill Development in the Fourth Industrial Revolution (Industry 4.0). IUP Journal of Information Technology 15(4), 7-30.

Deloitte (2015) Industry 4.0. Challenges and solutions for the digital transformation and use of exponential technologies. Retrieved January 20, 2021, from https://www2.deloitte.com/content/dam/Deloitte/ch/Documents/manufacturing/ch-enmanufacturing-industry-4-0-24102014.pdf.

Dombrowski, U., \& Wagner, T. (2014). Mental strain as field of action in the 4th industrial revolution. Procedia CIRP, 17, 100-105.

European Qualification Framework (2017) Council Recommendation of 22 May 2017 on the European Qualifications Framework for lifelong learning and repealing the recommendation of the European Parliament and of the Council of 23 April 2008 on the establishment of the European Qualifications Framework for lifelong learning. Official Journal of the European Union. Retrieved January 20, 2021, from https://eur-lex.europa.eu/legalcontent/EN/TXT/HTML/?uri=CELEX:32017H0615(01)\&from=EN

Hecklau, F., Galeitzke, M., Flachs, S., \& Kohl, H. (2016). Holistic approach for human resource management in Industry 4.0. Procedia CIRP 54, 1-6.

Hecklau, F., Orth, R., Kidschun, F., \& Kohl, H. (2017). Human Resources Management: MetaStudy - Analysis of Future Competences in Industry 4.0. In Proceedings 13th European Conference on Management Leadership and Governance, 163-174. 
Hernandez-de-Menendez, M., Morales-Menendez, R., Escobar. C.A., \& McGovern, M. (2020) Competencies for Industry 4.0. International Journal for Interactive Design and Manufacturing, 14, 1511-1524. https://doi.org/10.1007/s12008-020-00716-2

Hwang, G-J., Wu, P-H., \& Chen Ch-Ch. (2012) An online game approach for improving students' learning performance in web-based problem-solving activities. Computers \& Education. 59, 1246-1256. https://doi.org/doi:10.1016/j.compedu.2012.05.009

Kaasinen, E., Schmalfuß, F., Özturk, C., Aromaa, S., Boubekeur, M., Heilala, J., ... Walter, T. (2020) Empowering and engaging industrial workers with Operator 4.0 solutions. Computers \& Industrial Engineering. 139, 3-13. https://doi.org/10.1016/j.cie.2019.01.052

Kazançoğlu, Y., \& Özkan-Özen, Y.D. (2018) Analyzing Workforce 4.0 in the Fourth Industrial Revolution and proposing a road map from operations management perspective with fuzzy DEMATEL. Journal of Enterprise Information Management, 31(1), 891-907. https://doi.org/ 10.1108/JEIM-01-2017-0015

Kinkel, S., Schemmann, B., \& Lichtner, R. (2017). Critical Competencies for the Innovativeness of Value Creation Champions: Identifying Challenges and Work-integrated Solutions. Procedia Manufacturing, 9, 323-330.

Lorenz, M., Rüssmann, M., Strack, R., Lasse Lueth, K., \& Bolle, M. (2015), Man and Machine in Industry 4.0: How Will Technology Transform the Industrial Workforce Through 2025?, Consulting Group, Boston. Retrieved January 20, 2021, from http://imagesrc.bcg.com/Images/BCG_Man_and_Machine_in_Industry_4_0_Sep_2015_tcm9-61676.pdf

Merchant, Z., Goetz, E.T., Cifuentes, L., Keeney-Kennicutt, W., \& Davis, TJ. (2013) Effectiveness of virtual reality-based instruction on students' learning outcomes in K-12 and higher education: A meta-analysis. Computers \& Education. 70, 29-40. http://dx.doi.org/10.1016/j.compedu.2013.07.033

Mian, S.H., Salah, B., Ameen, W., Moiduddin, K., \& Alkhalefah, H. (2020). Adapting Universities for Sustainability Education in Industry 4.0: Channel of Challenges and Opportunities. Sustainability, 12(15), 1-31. https://doi.org/10.3390/su12156100

Miranda, J., López, C. S., Navarro, S., Bustamante, M. R., Molina, J. M., \& Molina, A. (2019). Open innovation laboratories as enabling resources to reach the vision of education 4.0. In 2019 IEEE International Conference on Engineering, Technology and Innovation (ICE/ITMC) (pp. 1-7).

Müller, J.M., Kiel, D., \& Voigt, K.-I. (2018). What Drives the Implementation of Industry 4.0? The Role of Opportunities and Challenges in the Context of Sustainability. Sustainability, 10(1), 247. https://doi.org/10.3390/su10010247

Nga, J.K.H. \& Shamuganathan, G. (2010) The Influence of Personality Traits and Demographic Factors on Social Entrepreneurship Start Up Intentions. Journal of Business Ethics. 95(2), 259282. https://doi.org/10.1007A10551-009-0358-8

Philbeck, T., \& Davis, N. (2018). THE FOURTH INDUSTRIAL REVOLUTION: SHAPING A NEW ERA. Journal of International Affairs, 72(1), 17-22. https://doi.org/10.2307/26588339

Quattrociocchi, B., Mercuri, F., D'Arcangelo, D., \& Cristini, V. (2018). Knowledge management to compete in the digital era: Skills evolution of enterprise systems. In Proceedings of the European Conference on Knowledge Management, 2, 733-740.

Ramirez-Mendoza, R. A., Morales-Menendez, R., Iqbal, H., \& Parra-Saldivar, R. (2018). Engineering Education 4.0: - proposal for a new Curricula. In 2018 IEEE Global Engineering Education Conference (EDUCON), 1273-1282. https://doi.org/10.1109/EDUCON.2018.8363376 
Rauch, E., Linder, Ch., \& Dallasega, P. (2020) Anthropocentric perspective of production before and within Industry 4.0. Computers \& Industrial Engineering, 139. https://doi.org/10.1016/j.cie.2019.01.018

Saha V., Mani, V., \& Goyal P. (2019) Emerging trends in the literature of value co-creation:

a bibliometric analysis. Benchmarking: An International Journal, 27(3), 981-1002. https://doi.org/10.1108/BIJ-07-2019-0342

Schneider, P. (2018). Managerial challenges of Industry 4.0: an empirically backed research agenda for a nascent field. Review of Managerial Science, 12(3), 803-848. https://doi.org/10.1007/s11846-018-0283-2

Schumacher, A., Erol, S., \& Sihn, W. (2016) A maturity model for assessing Industry 4.0 readiness and maturity of manufacturing enterprises. Procedia CIRP, 52, $161-166$. https://doi.org/10.1016/j.procir.2016.07.040

Simic, M., \& Nedelko, Z. (2019) Development of competence model for industry 4.0: A theoretical approach. In Economic and Social Development (Book of Proceedings), 37th International Scientific Conference on Economic and Social Development, 1288-1298.

Skinner, D., Saunders, M. N., \& Beresford, R. (2004). Towards a shared understanding of skill shortages: differing perceptions of training and development needs. Education+ Training, 46(4), 182-193. https://doi.org/10.1108/00400910410543973

Subotnik, R.F., Olszewski-Kubilius, P., \& Worrell, F.C. (2011) Rethinking Giftedness and Gifted Education: A Proposed Direction Forward Based on Psychological Science. Psychological Science in the Public Interest, 12(1), 3-54. https://doi.org/10.1177/152910061 1418056

Waller, M.A., \& Fawcett, S.E. (2013) Data Science, Predictive Analytics, and Big Data: A Revolution That Will Transform Supply Chain Design and Management. Journal of Business Logistics, 34(2), 77-84. https://doi.org/10.1111/jbl.12010

World Economic Forum. (2020). The Future of Jobs Report. Retrieved January 20, 2021, from http://www3.weforum.org/docs/WEF_Future_of_Jobs_2020.pdf 